\title{
L'hévéa en association avec les cultures pérennes, fruitières ou forestières: quelques exemples en Asie, Afrique et Amérique latine
}

Éric PenOT ${ }^{1}$

Isabelle OLLIVIER ${ }^{2}$

1 Cirad

Département Environnements

et sociétés

Umr Innovation

DR Cirad, BP 853

Anpandrianomby, 101 Antananarivo

Madagascar

\section{Supagro/Irc}

Domaine de Lavalette

Avenue du Val de Montferrand 34032 Montpellier

France

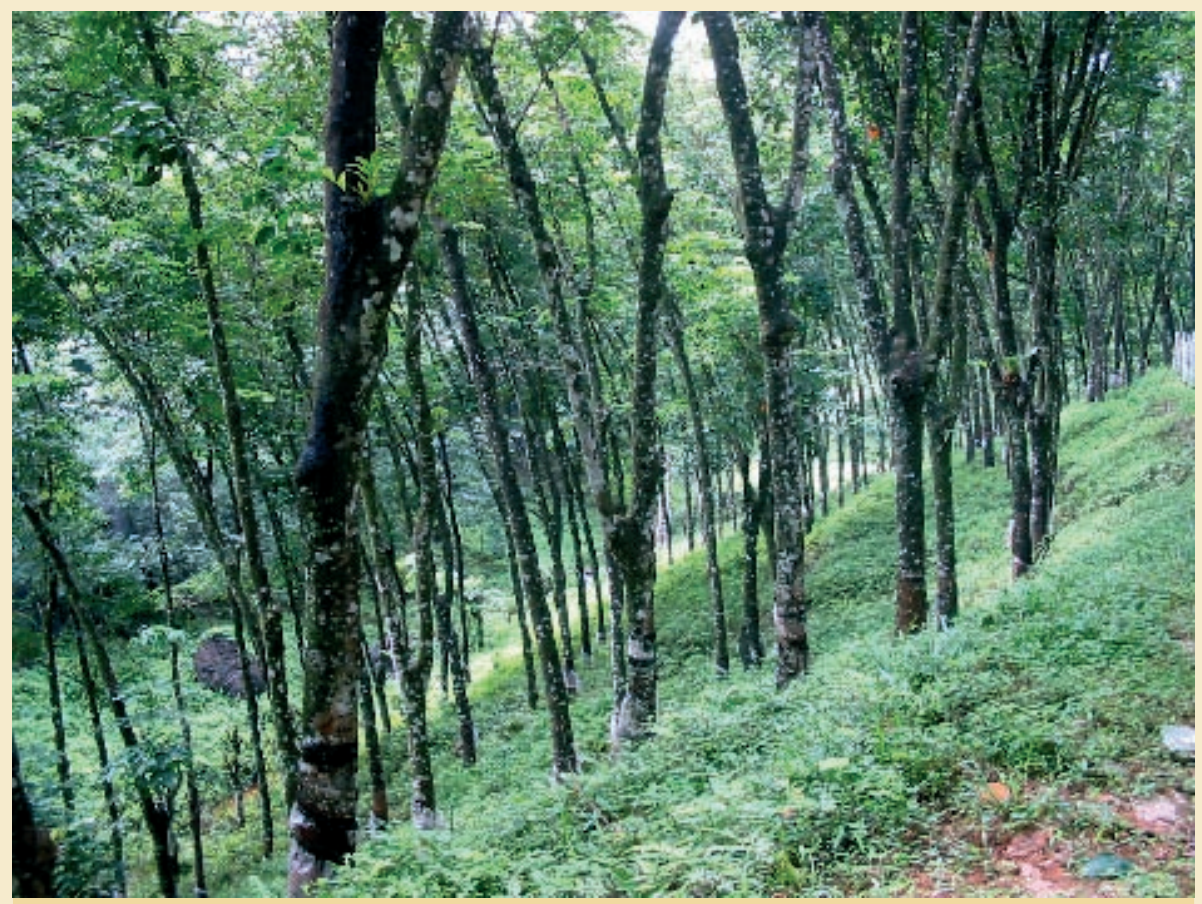

Photo 1.

Monoculture au Sri Lanka, 2005.

Photo E. Penot. 


\section{RÉSUMÉ}

\section{L'HÉVÉA EN ASSOCIATION AVEC LES CULTURES PÉRENNES, FRUITIÈRES OU FORESTIĖRES : QUELQUES EXEMPLES EN ASIE, AFRIQUE ET AMÉRIQUE LATINE}

Initialement développée par le secteur des grandes plantations au début du siècle, l'hévéaculture est aujourd'hui principalement le fait de petites exploitations paysannes. Le modèle de diffusion initial fut la monoculture stricte. Cependant, les cultures vivrières intercalaires pendant la période immature de l'hévéa, Hevea brasiliensis, sont relativement bien développées, y compris dans les anciens projets de développement sectoriels. En revanche, les associations incluant des cultures pérennes ou forestières sont peu recensées et souvent peu acceptées par les institutions de développement, comme ce fut le cas en Indonésie durant années 1990. Elles existent localement, parfois sur des superficies importantes : le "jungle rubber », par exemple. Ces pratiques assurent pourtant une meilleure valorisation de la terre et de la main-d'œuvre et les associations permanentes avec des cultures pérennes constituent un facteur de stabilisation économique des plantations et de diversification des revenus. Les systèmes agroforestiers complexes constituent aussi un avantage écologique puisqu'ils sont garants du maintien d'une grande partie de la biodiversité rencontrée en forêt naturelle. Le peu d'intérêt officiellement reconnu pour ces associations malgré des avantages économiques et environnementaux peut être imputé au fait qu'elles ne correspondent pas au type d'hévéaculture dominant au sein des grandes sociétés de plantations et des institutions de développement. Nombre de paysans ont innové et mis au point des systèmes astucieux et pratiques leur permettant de diminuer les risques et de diversifier leur production. Le présent article tend à faire le point sur les associations existantes : hévéa associé au café, au thé, au cacao, au rotin ainsi qu'aux espèces fruitières ou forestières. II ne prétend pas analyser les systèmes en détail mais a pour objectif d'en présenter la diversité.

Mots-clés : hévéa, association culturale, espèce pérenne, espèce fruitière, espèce forestière, agroforesterie, Afrique, Amérique latine, Asie.

\section{ABSTRACT}

\section{RUBBER TREE INTERCROPPING WITH FOOD-CROPS, PERENNIAL, FRUIT AND TREE CROPS: SEVERAL EXAMPLES IN ASIA, AFRICA AND AMERICA}

Initially developed by the Estate sector at the beginning of the century, most rubber tree plantings are from the smallholder sector. The initial model of diffusion was based on a strict monoculture. However, intercropping with annual food crops during the immature period of rubber tree, Hevea brasiliensis, are relatively well developed, including in rubber projects. On the other hand, the associations with perennial or forestry crops are rarely listed and often with little recognition from development institutions as it was the case in Indonesia during the 1990's. Such systems do exist locally, sometimes on a relatively important area such as the "jungle rubber" system for example. These agroforestry practices ensure a better land and labour valorization. Permanent associations with perennial crops during mature period constitute an economic factor of stabilization and diversification of income. The complex agroforestry systems have also ecological advantages guaranteeing maintenance of a part of forest biodiversity. The lack of interest officially recognized for these associations in spite of economic and environmental advantages can be charged to the fact that such systems do not correspond to the dominating Estate and development projects rubber tree model. Many farmers innovated and developed pragmatic systems with agroforestry practices enabling them to decrease risks and to diversify their productions. This article tends to give a progress report on existing associations of rubber tree with food crops, coffee, tea, cocoa, rattan, fruit and timber trees or other forest species. It does not claim to analyze all systems in detail but provide an idea of the diversity of associations.

Keywords: rubber tree, intercropping system, perennial species, fruit trees, forest trees, agroforestry, Africa, Latin America, Asia.

\section{RESUMEN}

\section{HEVEA ASOCIADO CON CULTIVOS PERENNES, FRUTALES 0 MADERABLES; ALGUNOS EJEMPLOS EN ASIA, ÁFRICA Y AMÉRICA LATINA}

Inicialmente desarrollado por las grandes plantaciones de principios del siglo pasado, el cultivo de hevea suele estar hoy en manos de pequeñas explotaciones campesinas. En un principio, el modelo seguido fue el de monocultivo estricto. Sin embargo, los cultivos alimenticios intercalares durante el período inmaduro del árbol, Hevea brasiliensis, están relativamente bien desarrollados, incluso en antiguos proyectos de desarrollo sectorial. Por el contrario, las asociaciones con cultivos perennes o maderables son escasas y no suelen ser aceptadas por las instituciones de desarrollo, como sucedió en Indonesia en los años 90 . Se dan localmente, y a veces cubren áreas importantes como en el caso del "jungle rubber". No obstante, estas prácticas garantizan un mejor aprovechamiento de la tierra y de la mano de obra; además, las asociaciones permanentes con cultivos perennes son un factor de estabilización económica de las plantaciones y de diversificación de los ingresos. Los sistemas agroforestales complejos presentan, asimismo, una ventaja ecológica, ya que son garantes del mantenimiento de una gran parte de la biodiversidad que se encuentra en los bosques naturales. El escaso interés, oficialmente reconocido, que estas asociaciones despiertan, a pesar de sus ventajas económicas y ambientales, puede deberse a que no corresponden al tipo de cultivo de hevea predominante entre las grandes compañías de plantaciones y las instituciones de desarrollo. Muchos campesinos han innovado y puesto a punto ingeniosos sistemas y prácticas que permiten reducir los riesgos y diversificar su producción. El presente artículo intenta hacer un balance de las asociaciones existentes: hevea asociado con café, con té, con cacao, con ratán y con especies frutales o forestales. No pretende analizar los sistemas en detalle, sino mostrar su diversidad.

Palabras clave: hevea, asociación de cultivos, especies perennes, especies frutales, especies forestales, agroforestería, África, América Latina, Asia. 


\section{Introduction}

\author{
(1.20)
}

Originaire d'Amazonie, l'hévéa, Hevea brasiliensis, a été introduit en Asie du Sud-Est à la fin du XIXe siècle, laquelle assure aujourd'hui $95 \%$ de la production mondiale de caoutchouc naturel. Alors qu'au Brésil la production est à l'origine exclusivement de source extractiviste (entre 1850 et 1930), le développement de l'hévéaculture a été le fait du secteur des grandes plantations (19001950), puis, rapidement, celui des petits planteurs qui dépasse en superficie les grandes plantations dès le milieu des années 1930 en Indonésie, montrant ainsi une forte dynamique paysanne de plantation ; et cela sans l'aide de l'État (PENOt, 2001). Aujourd'hui, les plantations d'hévéas occupent près de neuf millions d'hectares, dont plus de trois millions et demi en Indonésie, avec $83 \%$ sous forme de plantations paysannes et, en moyenne, des parcelles de deux à cinq hectares par famille en Asie du Sud-Est. Alors que la monoculture s'avère être le système de culture de référence des grandes exploitations industrielles, les petits producteurs ont intégré l'hévéa aux systèmes de culture déjà existants et pratiquent souvent les associations culturales avec des cultures annuelles vivrières (riz pluvial, arachide..) ou fruitières semi-pérennes (bananes, ananas, manioc...), voire forestières. L'objectif de cet article n'est pas de détailler chaque système mais de montrer la diversité et la richesse des associations créées, développées, adoptées et diffusées par les petits producteurs familiaux ainsi que quelques exemples originaux d'essais en milieu paysan ou de grande plantation.

\section{Contexte: études et enquêtes}

Des études de modélisation des exploitations agricoles avec une identification des sources de revenus pour les exploitations hévéicoles en mutation en Indonésie et en Thaïlande ont été menées entre 2001 et 2006, qui ont montré, d'une part, la complémentarité entre hévéa et palmier à huile et, d'autre part, le financement de la replantation en agroforêt à hévéa améliorée par les revenus issus de ce dernier (PENOT, 2006 ; WULAN et al., 2006 ; SIMIEN, 2005 ; MARTIN, 2005 ; LECOMTE, 2001). La modélisation de différents systèmes de culture à base d'hévéa a aussi été faite par l'Irri ${ }^{1}$. Cette diversification des sources de revenus réduit au maximum les risques liés à la monoculture, en particulier en période de crise (PENOT, 2006). Si les avantages économiques ne sont pas présentés ici, il faut bien reconnaître qu'il y a plus de descriptions agronomiques ou botaniques des systèmes dans la littérature scientifique que de véritable analyse économique (à l'exception notable des travaux du projet Srap $^{2}$ ), particulièrement pour valoriser les produits autoconsommés dont l'impact est important sur les ménages : économie des matériaux pour la construction de la maison et l'amélioration sensible de l'alimentation. Enfin, la diversité des situations écologiques, économiques et sociales et les conditions particulières et spécifiques desquelles sont issus les systèmes agroforestiers n'autorisent pas une diffusion généralisée de ces systèmes.

Une approche méthodologique pragmatique a été utilisée pour présenter les pratiques culturales vis-àvis des systèmes agroforestiers "simples " (hévéa associé à un nombre réduit de plantes sur une ou deux strates, tels le café ou le cacao) et « complexes « (hévéa associé à un nombre important d'espèces sur plu-

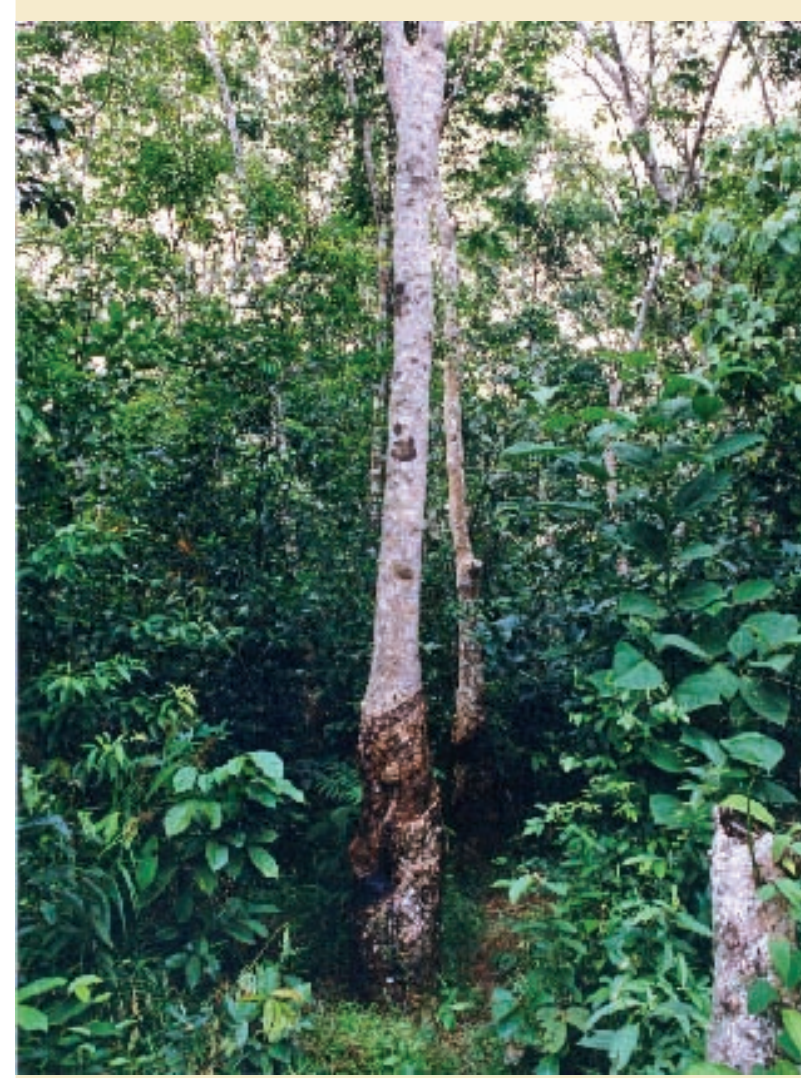

Photo 2.

Jungle rubber traditionnel en Indonésie, 1993.

Photo E. Penot.

sieurs strates de végétation) comparables de fait à une forêt, dénommée " agroforêt ", selon la typologie appropriée (MICHON, De ForestA, 1991). Cette typologie permet de séparer les systèmes où coexistent un nombre limité de plantes soit des interactions simples et éventuellement des externalités positives modérées des véritables agroforêts, soit des interactions complexes et des externalités positives fortes en termes de biodiversité, fertilité des sols et meilleure gestion de l'eau. Dans tous les cas, un système agroforestier à base d'hévéa est considéré avec au moins 100 arbres (fruits, bois, ou divers). Les densités observées s'échelonnent entre 100 et 300 arbres associés, le critère essentiel de l'association étant de limiter au maximum l'ombrage de l'hévéa afin de ne pas compromettre son potentiel de production.

\footnotetext{
1 Indonesian Rubber Research Institute.

2 Smallholder Rubber Agroforestry Programme.
} 


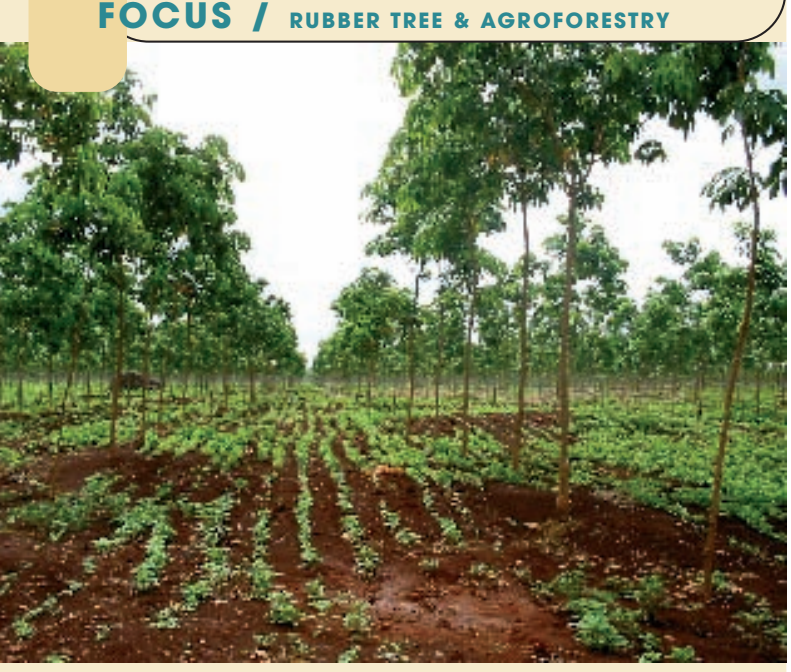

Photo 3.

Cultures intercalaires de sésame sur terres rouges au Vietnam, 2001. Photo E. Penot.

Le système agroforestier complexe le plus répandu est le « jungle rubber », un système de culture extensif où la forêt secondaire est associée à l'hévéa. Le système est basé sur du matériel végétal non sélectionné, d'où des rendements plutôt faibles, de l'ordre de $500 \mathrm{~kg} \mathrm{sec}$ par hectare et par an de caoutchouc. Les autres

Tableau I.

Pratiques agroforestières sur les parcelles en projet de développement à Ouest-Kalimantan.

Agroforesterie/type de projet

Réintroduction de pratiques agroforestières

Type d'arbre :

fruitiers

fruitiers + rente

cultures de rente

Nombre d'arbres associés :

2 à 10
11 à 100
plus de 100

Âge des hévéas au moment de

l'introduction des arbres associés : moins de 3 ans

4 à 7 ans

plus de 7 ans associations sont le plus souvent fondées sur des hévéas clonaux dont la productivité est généralement située entre 1000 et $1800 \mathrm{~kg} / \mathrm{ha}$ en agriculture familiale. Il est à préciser qu'aucun clone n'a jamais été spécifiquement sélectionné pour le milieu des petits producteurs ni pour les systèmes agroforestiers. Ces systèmes reposent sur le stock de clones disponible dont les caractéristiques sont compatibles avec l'usage souhaité en fonction du rendement attendu et des conditions locales. II n'existe pas de clones sélectionnés par critères d'usage : monoculture, grandes plantations, petits peuplements paysans ou agroforestiers.

Les paysans consultés en Thaïlande et en Indonésie n'observent pas de baisse significative de la production de caoutchouc dans les systèmes agroforestiers par rapport aux monocultures, ce qui est en partie corroboré par les résultats en station (Inde, Sri Lanka, Indonésie). La variabilité des situations et des ren-

$$
\text { Nes/Pir }
$$

(\%)

Sidp

Srdp/Tcsgp
$(\%)$

Approche partielle (\%)

\section{8}

44,5

51
72

28

0

62,5 25 12,5

0
2,5
2,5

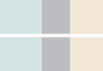

85,7

54,5

4,7
9,5

18,2

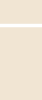

\begin{tabular}{|l|l|}
\hline 56 & 36,7 \\
\hline 34 & 40 \\
\hline 10 & 23,3 \\
\hline & \\
& \\
\hline 45,5 & 57,5 \\
\hline 27,3 & 42,5 \\
\hline 27,2 & 0 \\
\hline
\end{tabular}

dements en fonction des clones et des modalités de culture (dont l'impact de la qualité de saignée en particulier) est probablement plus significative que l'impact d'une éventuelle compétition entre hévéas et arbres associés si ces derniers ne sont pas situés au-dessus de la canopée de l'hévéa. Cette hypothèse reste cependant à vérifier au cas par cas.

Si beaucoup de systèmes incluent généralement des cultures vivrières annuelles (riz) ou pluriannuelles (banane, ananas) pendant les premières années, l'originalité de ces systèmes réside dans la combinaison multiple des espèces pérennes entre elles avec des usages parfois très différents : fruits, noix, bois de feu et bois d'œuvre, bois à autres usages (rotin), plantes médicinales, résine ou latex. Une enquête menée en 1997-1998 (CHAMBON, 2001) a montré que la réintroduction de pratiques agroforestières reste importante (et variable) dans les projets initialement centrés sur la monoculture (tableau I). Il est possible d'estimer qu'en 20013 à 5 \% des parcelles clonales plantées hors projet par les petits producteurs sont de nature agroforestière. Elles se trouvent en particulier en Ouest-Kalimantan et en Ouest-Sumatra où les Dayaks et les Minangkabau possèdent des traditions agroforestières culturellement et historiquement fortes (PENOT, 2001). Malgré le manque de documentation, cela est aussi observé au sud de la Thaïlande. Le Rrit ${ }^{3}$ a également travaillé sur des associations fruitiers et arbres à bois de valeur avec l'hévéa (BurathanAm et al., 1997).

La société Michelin a procédé à de très nombreux essais dans sa plantation du Mato Grosso au Brésil pour constater que les pratiques agroforestières s'avèrent potentiellement intéressantes pour une agriculture familiale soucieuse de diversifier ses revenus, mais ne le sont pas pour une société industrielle dont l'objectif est d'optimiser ses investissements.

Source : enquêtes B. Chambon, 1998-1999, Srap. 


\section{Intérêt des associations culturales}

\author{
Monoculture \\ ef jungle rubber
}

La monoculture stricte avec couverture de plantes légumineuses, principalement Pueraria phaseloides entre les rangs d'hévéa, est une pratique agricole satisfaisante (photo 1), en particulier pour les grandes plantations. En revanche, une période immature de cinq à sept années en monoculture clonale requérant capital et main-d'œuvre pour l'entretien est difficile à intégrer dans un système de production familial où la maind'œuvre et le capital sont limités (PEnot, 2001). Le problème de la génération d'un revenu en période immature est récurrent partout dans le monde et a suscité de nombreuses innovations par rapport au modèle original de la monoculture. Il est possible de séparer les stratégies paysannes et pratiques agroforestières en deux types : d'une part, celles limitées à la période immature pour des raisons techniques (réduction des entretiens...) ou économiques (générant un revenu complémentaire) et, d'autre part, celles qui sont utilisées pendant toute la durée du cycle de l'hévéa, mais avec des pratiques et des associations de plantes différentes pendant la période de production.

L'observation de l'évolution des pratiques en Indonésie entre 1993 et 2007 a mis en lumière des stratégies différenciées selon l'environnement politique et économique. Le coût de mise en place et d'entretien des plantations clonales entre 1980 et 1997 favorisait sans conteste les pratiques agroforestières moins intensives en capital et travail pour les petits producteurs hors projet. La crise économique (1997-2001) et la crise des prix mondiaux du caoutchouc (1997-2003) ont certes gelé la situation en limitant toute plantation, mais ont induit une certaine diversification. Par ailleurs, la baisse très importante $d u$ coût d'un herbicide (solution de $\mathrm{N}$ phosphonométhylglycine), efficace pour contrôler Imperata cylindrica, a limité le recours aux pratiques paysannes agroforestières améliorées proposées lors des années 1990, à savoir les "Ras " ou improved "Rubber agroforestry systems ». En revanche, le manque de bois d'œuvre et l'évolution récente de la réglementation autorisant les petits producteurs à couper et à commercialiser leurs arbres ont relancé, à partir de 2004, l'intérêt des plantations avec des espèces de valeur telles que le nyatoh, Palaquium sp.pl., le meranti, Shorea sp.pl., et le teck, Tectona grandis.

Avec les jungle rubber (photo 2), cette période dite immature dure de huit à quinze ans du fait de la compétition entre les hévéas non sélectionnés (issus de graines donnant des plants de type "seedlings ") et la repousse forestière. Les planteurs ne tirent alors aucun revenu durant cette période mais l'avantage du jungle rubber est qu'il ne requiert aucun intrant ni investissement en travail durant la période immature. Un capital inexistant, une faible main-d'œuvre marginale et une absence de risques majeurs sont les principales raisons qui expliquent le succès de l'hévéa depuis son introduction dans ces régions et qui justifient l'existence durable de traditions agroforestières indonésiennes. Si le caoutchouc reste le moteur financier principal, d'autres produits (fruits et noix, bois de feu, bois d'œuvre, rotin, plantes médicinales...) permettent la diversification des revenus.

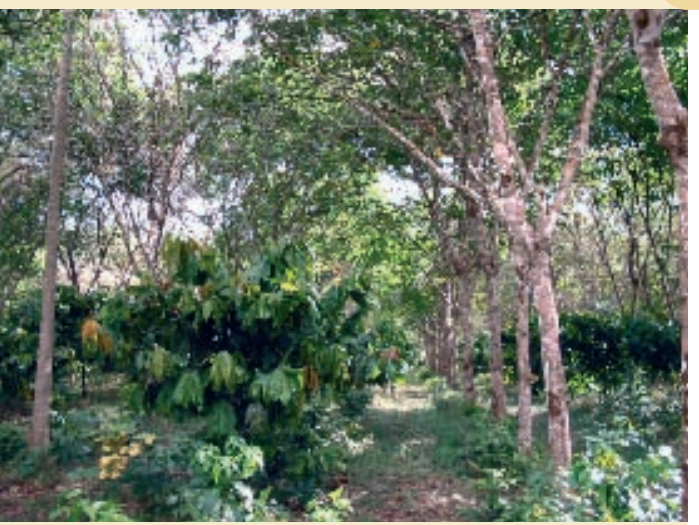

Photo 4.

Cacao en intercalaire d'hévéa à Uruara en Amazonie, 2003. Photo E. Penot.

\section{Les cultures annuelles en intercalaire ou la valorisation de l'investissement pendant la période immature}

L'introduction de cultures intercalaires au pied de jeunes hévéas permet d'assurer aux planteurs un certain niveau d'autosuffisance alimentaire, voire un revenu supplémentaire par la vente de surplus, et ainsi de surmonter en partie la période de soudure. En outre, la pratique des cultures associées a le plus souvent eu un effet bénéfique sur l'hévéa ainsi que l'ont montré les travaux dans différents pays par les projets européens STD II et III (Systèmes techniques et développement) lors des années 1990 (WIBAWA, 2000). La fertilisation et l'entretien procurés aux autres cultures accélèrent la croissance de l'hévéa. À présent, aucun obstacle institutionnel n'entrave la vulgarisation des cultures annuelles intercalaires et nombre de projets reconnaissent la validité du concept ; et cela avec une variété infinie de combinaisons liées aux marchés (piment ou ananas, maraîchage et tubercules), à la sécurité alimentaire (sésame ; photo 3). Il est à noter que des pays tels que la Malaisie ont développé une industrie de traitement du bois d'hévéa pour l'ameublement qui valorise les plantations en fin de rotation, permettant de financer la replantation clonale et la mise en place de ces cultures intercalaires sur un ou deux ans. 
raccourcie. Le choix d'une pratique agroforestière sous ombrage relève ainsi d'une stratégie paysanne d'étalement de la production sur un pas de temps plus long en préservant le capital de production, alors que la plantation plein soleil privilégie le court et moyen terme en optimisant le retour sur investissement.

Au Ghana, les systèmes agroforestiers reposent, eux aussi, sur le choix d'un ombrage modéré avec quelques arbres fruitiers ou de valeur pour leur bois (Ruf et al., 2006). Une tendance récente montre l'intérêt pour la plantation en mélange avec des arbres de valeur commerciale à croissance rapide : le cedrela, Cedrela odorata, ou le fraké, Terminalia superba (РENOT, 2005 a).

L'avenir de l'association cacaohévéa repose assurément sur les systèmes à très large écartement, de 12 à $18 \mathrm{~m}$ entre les lignes avec deux à trois rangées d'hévéa (comme pour le café, le thé, le durian et les fruitiers), mais qui sont encore très peu développés.

\section{Le café}

Avec le café et le thé, la problématique est la même que pour le cacao en association avec l'hévéa. Ces trois plantes peuvent accepter l'ombrage en fonction de l'orientation technique décidée par le producteur (plein soleil ou ombrage partiel) mais ne peuvent guère subir l'ombrage trop intense d'une plantation d'hévéa mise en place à forte densité et faible écartement.

Au Brésil, dans le cadre de plantations privées, sont présentes des associations hévéa-café pour une dizaine d'années, mais l'hévéa est destiné à remplacer le café. En Chine, à Hainan, le café arabica est planté suivant une densité standard de 5000 plants par hectare (deux rangs avec des interlignes de $10 \mathrm{~m}$ entre les hévéas, quatre pour des interlignes de $15 \mathrm{~m}$ ). Cette association est mise en place par des petits planteurs pour une durée de huit ans, car au-delà la compétition interspécifique et l'ombrage de l'hévéa sont

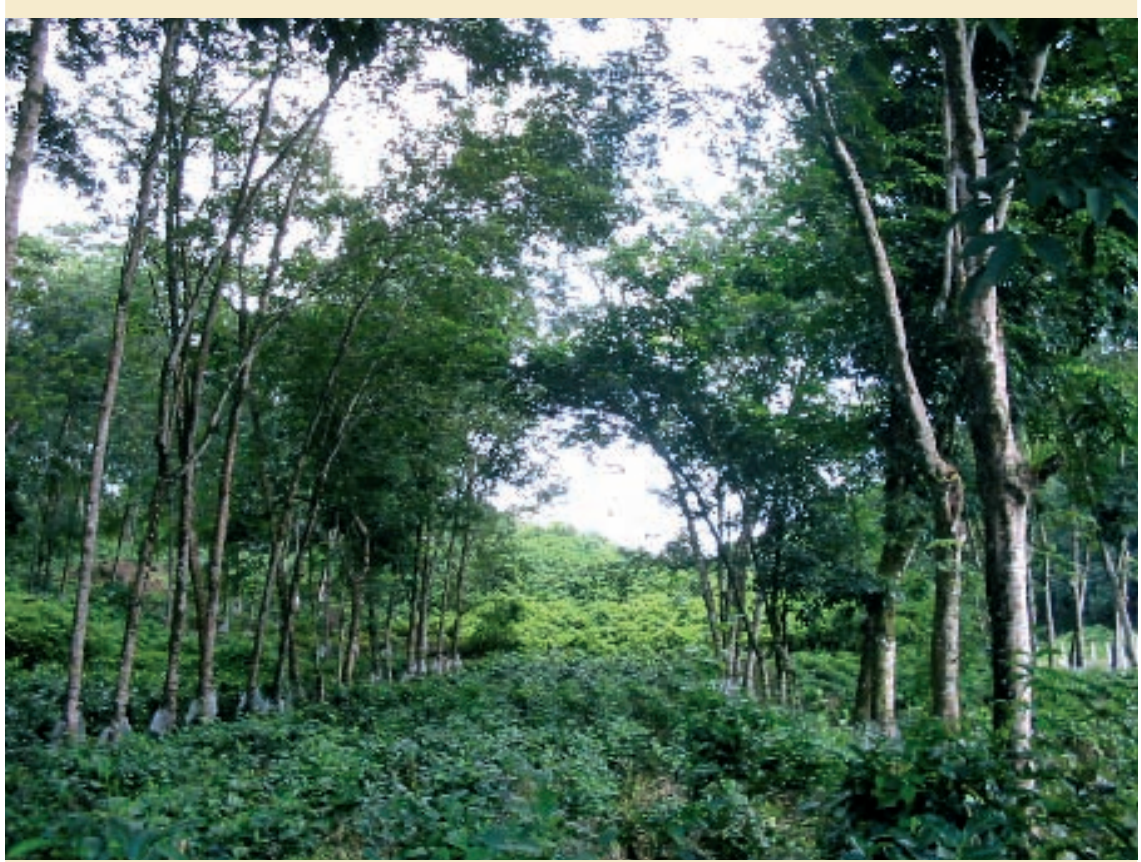

Photo 6.

Thé en intercalaire d'hévéa en interligne normal de 7 m au Sri Lanka, 2005. Photo E. Penot.

\section{Le poivre}

rédhibitoires pour les caféiers. Il se peut qu'une troisième culture soit intégrée : l'ananas (SAINT PIERRE, 1989). Globalement, le café, comme le cacao, n'est pas intéressant avec l'hévéa en système intercalaire traditionnel (6 m). Au Brésil, le café est souvent planté pour succéder aux peuplements d'hévéa dont les rendements faiblissent sous la pression de Microcyclus ulei, et cela malgré l'utilisation de variétés tolérantes.

Des essais menés en Côte d'Ivoire (photo 5) n'ont pas montré d'incidence négative sur le niveau de production de l'hévéa, quel que soit le système, puisque le caféier reste toujours dans la strate inférieure. Les rendements des caféiers sont comparables ou supérieurs à ceux obtenus en culture pure avec les techniques de culture en double interligne et large écartement, du moins pour les quinze premières années. Par contre, les rendements chutent en écartement classique dès la cinquième année.
Le poivre est une culture exigeante en intrants et travail (palissade, fertilisation, irrigation). Il est intéressant de l'associer avec l'hévéa du fait de l'effet de couvert et de protection des poivriers contre le vent et le froid. En Chine (et ailleurs), cette culture est celle procurant à l'agriculteur le plus fort retour économique par unité de surface (SAINT PIERRE, 1989). Le poivre est, à Hainan, planté pour une quinzaine d'années suivant un arrangement de deux rangs au sein de larges interlignes de $12 \mathrm{~m}$. Les interactions avec l'hévéa pour l'ombre et les racines sont les mêmes que celles rencontrées avec le café après la dixième année. Le poivre est une culture majeure des systèmes agroforestiers à base de poivre et d'acajou ou de castanha brésilienne (noix de pécan), en remplacement des vieilles plantations d'hévéa des fronts pionniers amazoniens, notamment dans la région d'Uruara. 


\section{Le thé}

Parmi toutes les cultures pérennes intercalaires, le thé (étudié dès les années 1960) est, sans conteste, le plus propice. La lumière apportée aux théiers lors de la défoliation de l'hévéa est favorable à la production de thé durant cette période. Le thé en tant que plante d'accompagnement induit une augmentation de 10 à $20 \%$ du taux d'éléments minéraux dans le sol, réduit la perte en eau et maintient la litière. De ce fait, le système radiculaire de l'hévéa en monoculture est de moitié inférieur à celui qu'il développe avec du thé en association, présentant ainsi de meilleures croissance et production. Le thé est une culture traditionnelle en association en Chine (Courbet, 1996) et au Sri Lanka (PENOT, 2005 b). Le rendement du théier est plus faible du fait de l'ombrage, mais la qualité du thé est supérieure. L'invasion par Imperata cylindrica est évitée grâce à la compétition interspécifique et au maintien du couvert au sol. Les prix du thé et de l'hévéa sont fixés en Chine par le gouvernement et cette situation très particulière interdit toute extrapolation.

Au Sri Lanka, des essais de thé en plantation avec l'hévéa sont menés depuis 1985, notamment suivant les systèmes à large intercalaire, sans concurrence significative vis-à-vis de l'hévéa au cours des trois premières années. Toutefois, des contraintes sont à prendre en compte : le thé doit être planté au moins $300 \mathrm{~m}$ au-dessus du niveau de la mer. Par contre, au dessus de $600 \mathrm{~m}$, les conditions sont marginales pour l'hévéa alors que c'est audessus de cette altitude que la qualité du thé est la meilleure, d'où la difficulté de combiner les deux cultures. Théoriquement, la niche écologique permettant une association optimale est étroite, mais en réalité le développement très important depuis la fin des années 1990 des marchés des thés de basse qualité cultivés en basse altitude pour le Moyen-Orient et le Pakistan a permis de telles associations entre 300 et $600 \mathrm{~m}$. Toutefois, un certain arrangement spatial est à respecter afin d'éviter l'effet d'ombre excessif de l'hévéa

sur le thé (système à écartement classique ; photo 6). Les seuls systèmes ayant un avenir sont ceux à double ligne d'hévéa et très large interligne, de 15 à $20 \mathrm{~m}$, permettant une production significative du thé (photo 7). Économiquement, le planteur retire une marge nette à l'hectare satisfaisante en dépit de densités de mise en place des deux cultures légèrement inférieures à celles de la monoculture. Une étude menée par l'auteur en 2004 pour le compte de la Banque mondiale a fait ressortir que les paysans, ainsi que de plus grandes entreprises, commençaient à s'intéresser à ce système permettant de compenser les variations de prix des produits, dans cette zone charnière comprise entre 300 et $600 \mathrm{~m}$. Effectivement, du fait de la forte volatilité des prix du caoutchouc et du thé, la diversification des revenus issue de cette double culture permet de mieux amortir les crises, ce qui constitue un net avantage par rapport aux monocultures spécifiques, les systèmes agroforestiers étant plus résilients à moyen terme.

\section{Le rotin}

À l'état naturel, ce palmier grimpant (Calamus manan) nécessite un tuteur, rôle que peut jouer l'hévéa. Les résultats des essais sont encourageants avec le rotin qui présente une croissance supérieure à celle obser- vée en milieu naturel forestier, avec un coût d'établissement et d'entretien relativement bas. Le retour sur investissement est globalement intéressant pour les trois pays où ce dispositif a été développé (Philippines, Malaisie et Indonésie). L'association hévéarotin a été envisagée au début des années 1990 en Indonésie (MICHON, De Foresta, 1991). La station de recherche Sungei Putih (Irri, NordSumatra) d'Indonésie a réalisé des essais intéressants mais ils montrent que le rotin ne peut être planté qu'en fin de cycle de l'hévéa et non au début car la récolte du rotin est extrêmement dommageable pour les hévéas ; des résultats similaires ont été constatés aux Philippines avec des semis de variétés locales récoltés en forêt (IMBACH, 1995). L'expérience a été tentée à large échelle à Kalimantan par le projet Srdp (Smallholder rubber development project) à partir de 1997 (photo 8) mais avec des résultats mitigés. En 1980 furent menés les premiers essais en Malaisie, qui détient 104 des 600 espèces de rotin disponibles dans le monde. La demande en rotin est importante dans ces pays avec une industrie du meuble conséquente. La raréfaction de la collecte extractiviste devrait permettre de relancer ce type d'association à condition d'introduire le rotin en fin de cycle de l'hévéa, à partir de la vingt-cinquième année. 


\section{Associations recensées avec des fruitiers et des espèces forestières}

\section{Association avec les arbres fruitiers}

Généralement, les fruitiers prennent une place importante au sein des peuplements d'hévéa, avec des espèces locales dans l'interligne comme dans les jungle rubber en Indonésie ou avec des arbres greffés tels que le durian en Thaïlande. À Mindanao, aux Philippines, des fruitiers et les espèces forestières sont utilisés en mélange : durian, Durio zibethinus, langsat/duku, Lansium domesticum, et ramboutan, Nephelium lappaceum, avec fructification tardive de douze à quinze ans. Le manguier, Mangifera indica, a une période de fructification correspondant à l'hivernage de l'hévéa dans cette zone.

En Thaïlande, l'hévéa est parfois associé au durian, au mangoustan, Garcinia mangostana, au ramboutan et au jacquier, Artocarpus heterophyllus. Le Rrit expérimente des combinaisons entre hévéas, fruitiers et le neem (Azadirachta excelsa) pour la production de bois (Buranatham et al., 1997). Le thang, Litsea grandis, le khayom, Shorea roxburghii, et le thamsao, Fagraea fragans, représentent également un haut potentiel pour l'agroforesterie car ils sont non seulement très tolérants pour l'ombrage et mais aussi à usages multiples pour le bois. Les repousses naturelles au sein des monocultures sont également favorisées. Dans la province de Pangla, des jungle rubber de plus de quarante ans sont enrichis en bambou, rotin et autres " arbres multi-usages ». Les parcelles de la région de Hat Yai montrent de nouveaux systèmes avec du goyavier, Psidium guajava, irrigué ou des duku, Aglaia sp.pl., en pleine production à dix ans (photo 9).

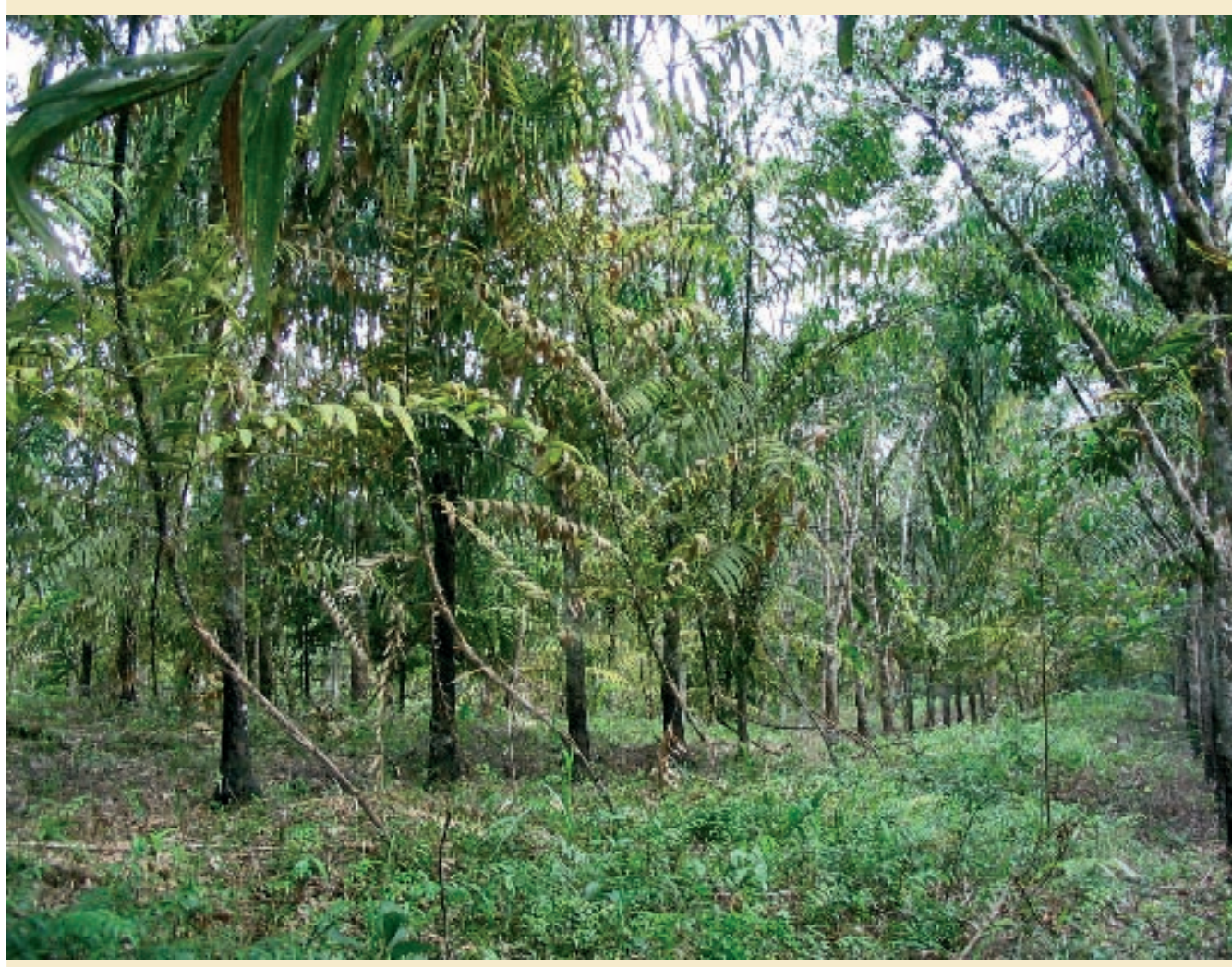

Photo 8.

Rotin en intercalaire d'hévéas de 8 ans, interligne normal de $6 \mathrm{~m}$ et âge de 4 ans pour le rotin à Kalimantan-ouest en Indonésie, 1993.

Photo E. Penot.

En Indonésie, les paysans combinent hévéa et fruitiers/arbres à bois soit dans leurs plantations monoclonales (issues de projets Srdp), soit dans leur jungle rubber. À Sanjan (Ouest-Kalimantan), un tiers des paysans ont planté ou laissé se régénérer les espèces suivantes pour les fruits : pekawai et durian, Durio sp.pl., ramboutan, assam, Tamarindus spp., cempedak et mentawa, Artocarpus sp.pl., petai, Parkia speciosa, et pour les espèces forestières : belian, Eusideroxylon zwageri, nyatoh blanc et rouge, Palaquium sp.pl., ainsi que café et cacao ; la densité de plantation des arbres associés étant comprise entre 95 et 290 arbres par hectare pour 500 hévéas (photo 10). Les espèces concernées sont présentées dans le tableau II.

En Indonésie, le projet Srap a testé de nombreuses associations, en partenariat avec les communau- tés locales, telles que la reforestation d'un petit bassin versant dans le village de Bangkok, district de Pasaman, dans la province de SumatraOuest (photo 11). Les enquêtes (CHAMBon, 2001) ont montré que $40 \%$ des paysans du projet réintroduisent des fruitiers en intercalaire mais seulement $10 \%$ dans des proportions qui justifient l'appellation d'agroforêt (avec plus de 150 arbres associés par hectare). Le suivi des parcelles paysannes du projet depuis 1994 a cependant montré qu'en Indonésie l'intérêt s'est déplacé des fruitiers (photo 12) vers les arbres à bois d'œuvre à partir des années 2000 ; alors que c'est le contraire en Thaïlande du Sud où le marché des fruits est beaucoup plus développé qu'en Indonésie et où, en outre, les lieux de production sont concentrés autour des centres urbains de Hat Yai et Songhla. 


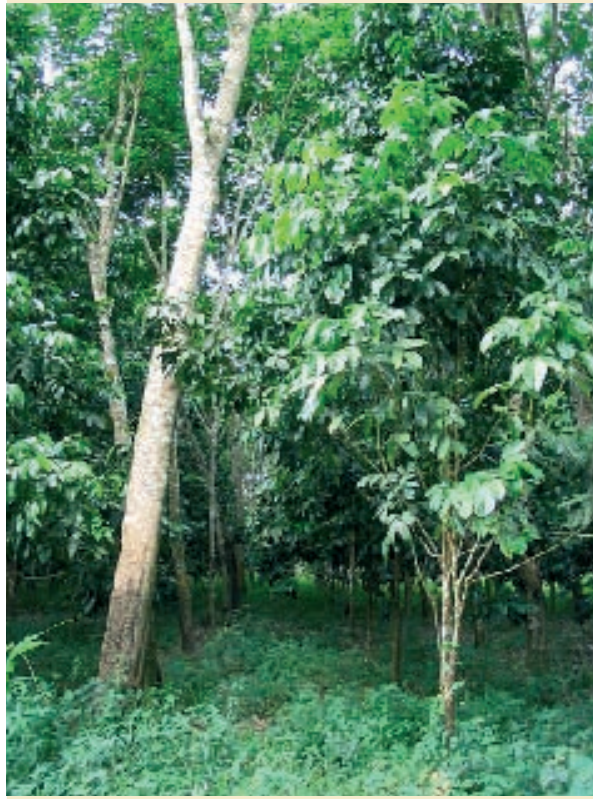

Photo 9.

Hévéa et duku (Aglaia sp.pl.) en production au sud de la Thaïlande, 2006.

Photo E. Penot.

En Chine, à Hainan, des associations entre hévéa et espèces brisevent (SAINT PIERRE, 1989) concernent une région parcourue par les typhons. Les arbres, Eucalyptus sp.pl et Acacia confusa, sont plantés à la densité de sept arbres à l'hectare, avec des espèces de moindre taille et à croissance plus lente pour former la strate inférieure.

L'association hévéa-fruitier est en place à titre expérimental en Malaisie (TAHUNAN, 1996) et en Thaïlande (photo 13) avec divers fruitiers dont le durian, le ramboutan, les jacquiers, le cempedak, Artocarpus integer, et le mangoustan, suivant des systèmes à densité de population et écartement variables (rangées simples, doubles ou triples dans un interligne de $22 \mathrm{~m}$ ). Ce sont ces systèmes qui ont manifestement le plus d'avenir dans les zones où il existe un marché et des filières fruitières bien organisées. De tels essais sont également testés au Cambodge. Enfin, la banane a été testée avec des résultats encourageants au Sri Lanka.

En Amazonie colombienne, l'hévéa constitue une alternative déjà ancienne à la culture de la coca (PEnot, 1999). Les cultures fruitières sont intéressantes car il existe un marché urbain pour le palmito et le chontaduro respectivement : cœur et fruit du palmier, Bactris gasipaes, et les fruitiers classiques de la région. Les techniques agroforestières per- mettent une lutte anti-Brachiaria spp. au moindre coût par l'ombrage ; celle-ci, faute de contrôle, s'avère très compétitive comme l'est Imperata cyclindrica en Asie. Les combinaisons actuelles les plus intéressantes seraient pour la strate inférieure : araza, Eugenia stipitata, copoazu, Theobroma grandiforum, borojo, Borojoa patinoi, Citrus sp.pl., sapotille, Annona muricata, maracujá, Passiflora edulis, et pour la strate supérieure : chontaduro, lulo amazonico, Solanum quitoense, uva caimarona, Spondias dulcis, avocatier, Persea gratissima, manguier, mangoustan, papaye, Carica papaya, tomate de arbol, Solanum betaceum, castaño, Sterculia sp.pl., les anones, Rollinia sp.pl., bacuri, Platonia insignis, et guaraná, Paulinia cupana.

Au Brésil sont recensées des associations hévéa-agrumes de façon permanente. Les plantations de l'entreprise Michelin du Mato Grosso comptent également des associations hévéa-palmito : de très nombreuses associations y ont été testées, mais aucune suite n'a été donnée à ces travaux par manque de rentabilité dans le cadre d'une grande plantation.

Tableau II.

Principales espèces fruitières conservées ou plantées dans les parcelles d'hévéa en Asie du Sud-Est.

\begin{tabular}{|c|c|}
\hline Arbres fruitiers & Avantages \\
\hline $\begin{array}{l}\text { Durian } \\
\text { (Durio zibethinus) }\end{array}$ & $\begin{array}{l}\text { Revenu et vente de fruits sur } \\
\text { marchés importants } \\
\text { Bois de grande valeur }\end{array}$ \\
\hline $\begin{array}{l}\text { Ramboutan } \\
\text { (Nephelium lappaceum) }\end{array}$ & Très importante demande locale \\
\hline $\begin{array}{l}\text { Jengkol } \\
\text { (Archidendron pauciflorum) }\end{array}$ & $\begin{array}{l}\text { Forte demande locale } \\
\text { Autoconsommation }\end{array}$ \\
\hline $\begin{array}{l}\text { Petai } \\
\text { (Parkia speciosa) }\end{array}$ & $\begin{array}{l}\text { Forte demande locale } \\
\text { Production dès la } 5^{\mathrm{e}} \text { année }\end{array}$ \\
\hline $\begin{array}{l}\text { Langsat/duku } \\
\text { (Lansium domesticum) }\end{array}$ & $\begin{array}{l}\text { Grosse demande et marché } \\
\text { important sur Sumatra et Java }\end{array}$ \\
\hline
\end{tabular}

Contraintes

Au maximum 20 arbres par hectare avec hévéa La production débute 15 ans après la mise en place

Même niche écologique et taille que l'hévéa Variétés locales plus adaptées aux conditions agroforestières mais qualité des fruits moindre

Même niche écologique et taille que l'hévéa Pas de variétés améliorées disponibles

La production débute 10 ans après plantation 


\section{Association avec les arbres à bois d'œuvre ou de service}

De nombreux systèmes intègrent en petit nombre des espèces à bois de valeur. Le cycle de croissance (temps de révolution) de ces derniers est souvent long, de l'ordre de trente à cinquante ans, à l'exception notable de certaines espèces à croissance rapide telles que l'eucalyptus. Le teck est potentiellement intéressant, en Thaïlande en particulier, car son cycle est similaire à celui de l'hévéa, mais leurs exigences écologiques respectives diffèrent nettement, ce qui constitue un facteur limitant pour préconiser ce mélange (TAHUNAN, 1996). Au Cambodge, un essai de 6 ha réalisé par l'Ircc ${ }^{4}$ est consacré à la culture d'arbres forestiers de haute valeur en association avec l'hévéa sur large intercalaire (âgé de trois ans en 2009). Au Ghana, certains arbres à croissance rapide sont également utilisés, à vocation de bois d'œuvre (tableau III), observés au sein d'agroforêts à base de cacaoyers.

Enfin, les arbres à croissance rapide peuvent être aussi cultivés pour le bois d'œuvre de basse qualité, pour le bois de feu ou tout simplement pour générer de l'ombrage afin de limiter l'envahissement de Imperata cylindrica, de Chromolena odorata ou de toute autre peste végétale. Les essences concernées, à croissance rapide, sont souvent le gmélina, Gmelina arborea, et Acacia mangium qui néanmoins sont des espèces concurrentielles pour l'hévéa. Les essais de mélange d'espèces en milieu paysan menés par le Srap à Kalimantan ont mis en évidence la nécessité de couper les arbres producteurs de bois après la quatrième année, sous peine d'un effet marqué sur la croissance et la production des hévéas (PENOT, ESCHBACH, 2005).

Les systèmes intégrant des arbres fruitiers ou arbres à bois d'œuvre sont à la limite entre agroforêts simples et complexes. Ils entrent dans cette dernière catégorie si le

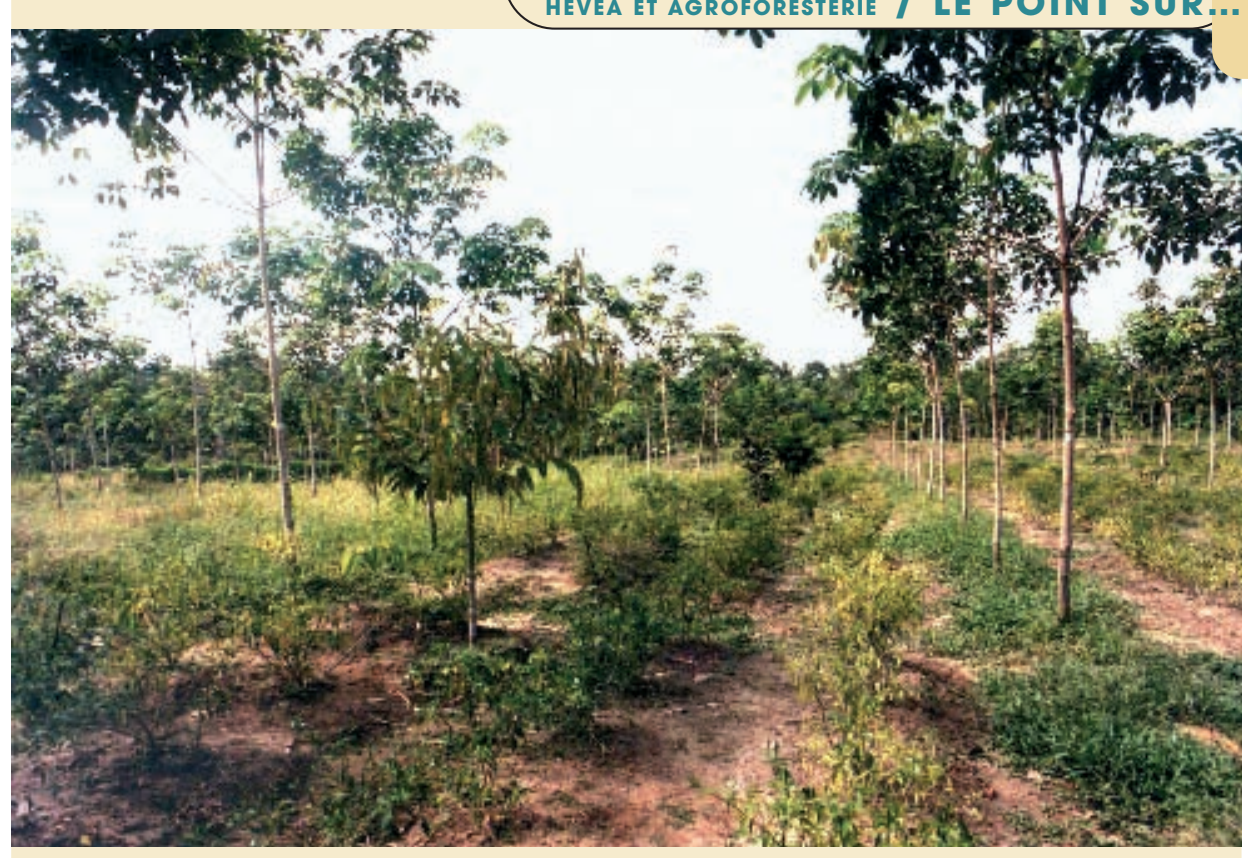

Photo 10.

Jeunes hévéas de 3 ans avec fruitiers et piment en intercalaire à Sanjan, dans la province de Kalimantan-ouest en Indonésie, 1993.

Photo E. Penot.

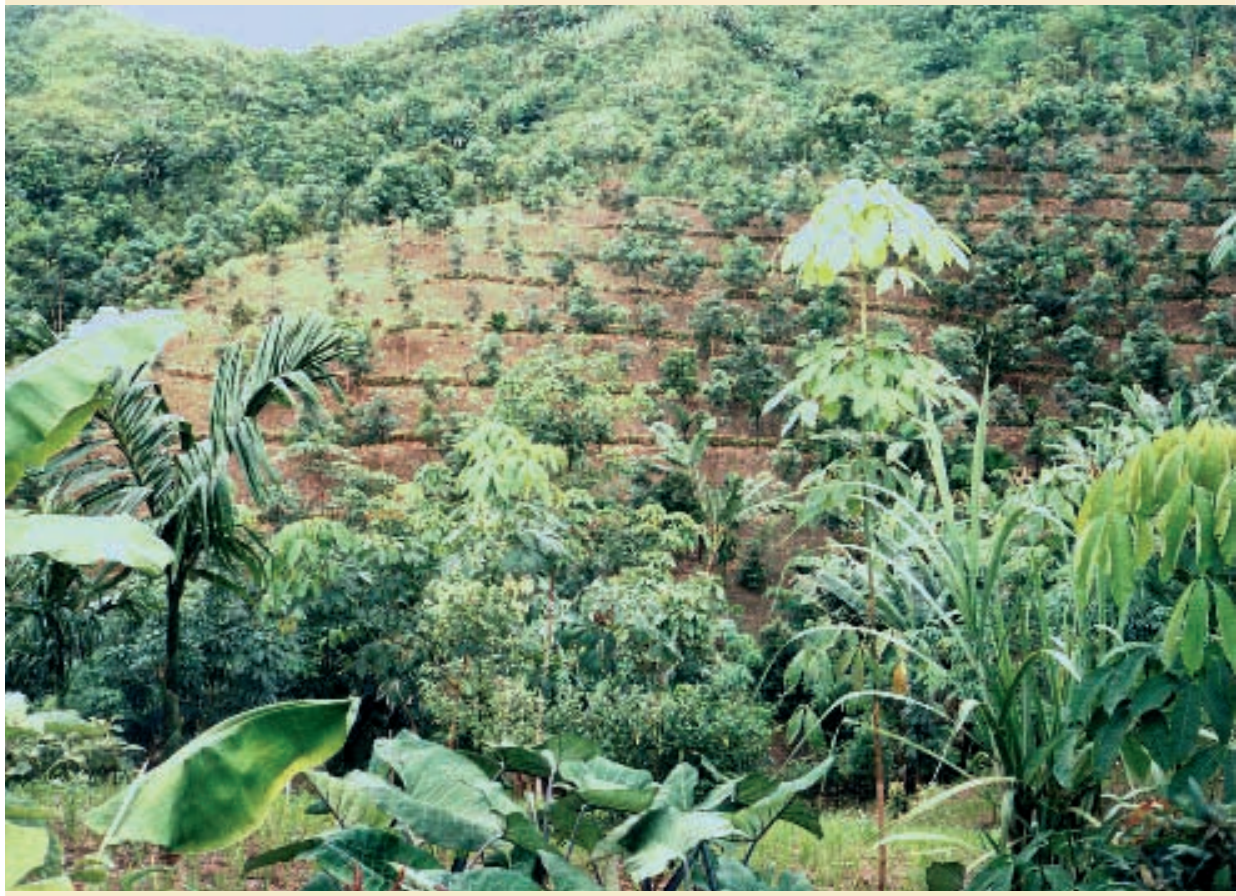

Photo 11.

Fruitiers (ramboutan, aréquier, bananier) et riz pluvial en intercalaire d'hévéa,

avec interligne normal de 6 m à Pasaman, à l'ouest de Sumatra en Indonésie, 1997. Photo E. Penot.

nombre d'espèces, de strates et la densité d'arbres sont conséquents par rapport à la culture dominante. Pour l'hévéa, à titre exemple, une densité moyenne de 500 hévéas par hectare et une densité de plus de
150 arbres associés par hectare sur plusieurs strates constitueraient alors une agroforêt dite « complexe », à condition d'avoir un nombre d'espèces important et une combinaison des espèces de type multistrate. 


\section{Les systèmes en double interligne}

Ces systèmes sont nés du constat de l'impact important de l’ombrage de l'hévéa, espèce à croissance rapide, sur certaines cultures associées dont le café, le thé, le cacao ou les agrumes. La double ligne d'hévéas permet de conserver un nombre minimum d'arbres à l'hectare (de l'ordre de 450 arbres) afin de ne pas pénaliser la production de caoutchouc tout en permettant des interlignes très larges (10 à 20 m) pour valoriser les cultures associées en plein soleil pendant au moins quinze ans. La contrainte reste l'entretien des interlignes pendant les années immatures de l'hévéa et des autres cultures pérennes associées (ou le capital pour le désherbage chimique). Les systèmes les plus développés sont ceux avec le thé au Sri Lanka (photo 17). Des expérimentations sont également en cours au Cambodge, couplées avec des systèmes de cultures annuelles à couverture végétale et semis direct.

Du fait d'une meilleure distribution de la lumière pour des productions associées plus intensives demandant soin et partage des ressources, et pour mieux valoriser les potentiels des variétés plantées, les systèmes à base de large écartement et double interligne ont sans nul doute un avenir important tant pour les grandes plantations que pour les petits producteurs familiaux. Ils représentent une forme de diversification (et souvent d'intensification) robuste et adaptée aux risques économiques et écologiques.

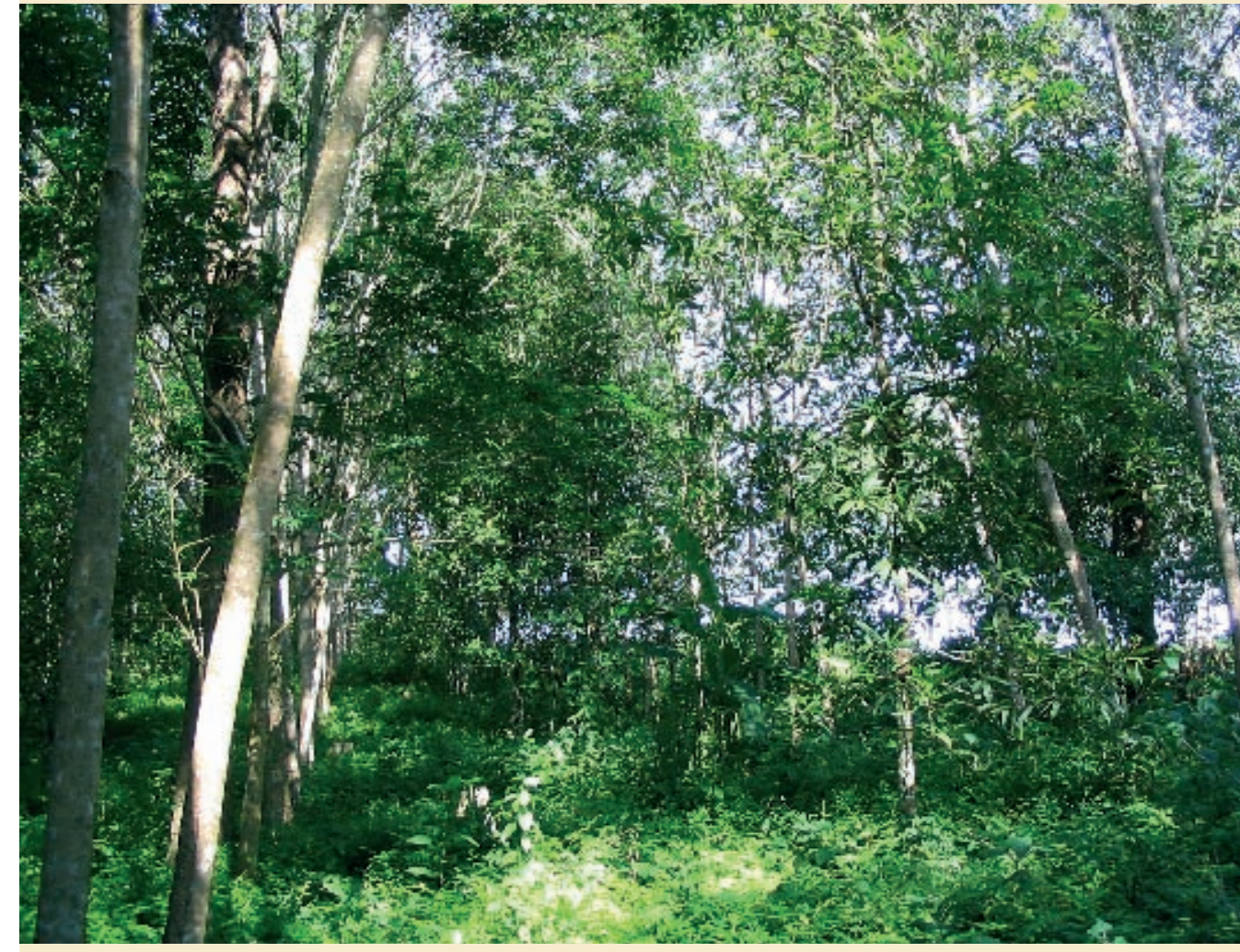

Photo 13.

Hévéas de 13 ans avec jacquier, mangoustan et ramboutan au sud de la Thaïlande, 2005.

Photo E. Penot.

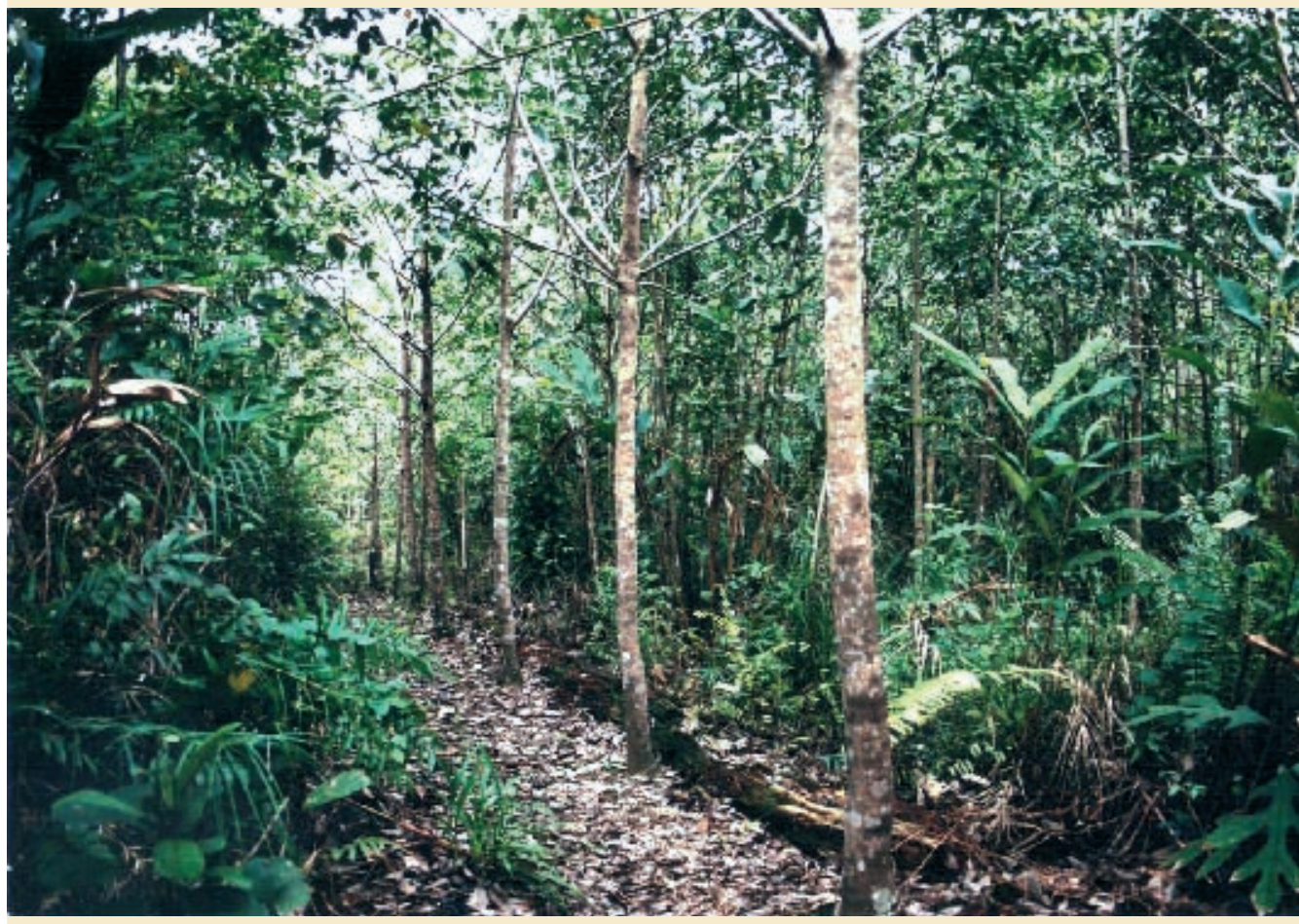

Photo 14.

Forêt secondaire en intercalaire d'hévéa clonal, interligne normal (type Ras 1),

à Engkayu, Kalimantan-ouest en Indonésie, 2001.

Photo E. Penot. 
FOCUS / RUBBER TREE \& AGROFORESTRY

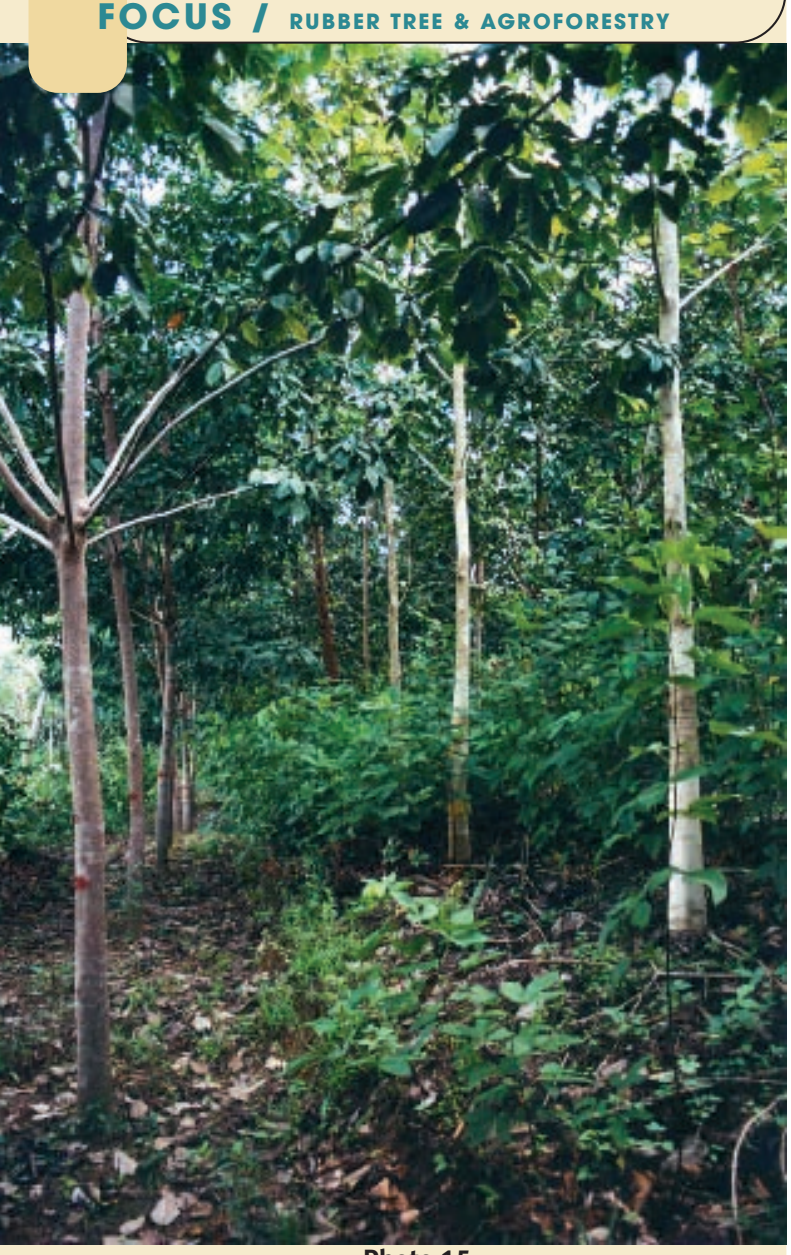

Photo 15.

Arbres pour ombrage à croissance rapide en intercalaire d'hévéa, interligne normal, Acacia mangium (type Ras 3.3), à Trimulia, Kalimantan-ouest en Indonésie, 2005.

Photo E. Penot.

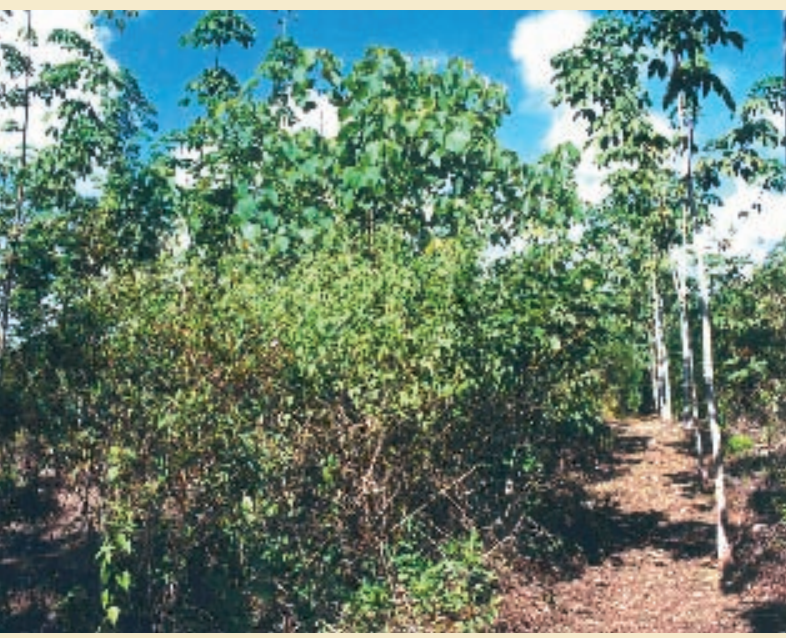

Photo 16.

Arbres pour ombrage à croissance rapide et fruitiers en intercalaire d'hévéa, interligne normal, mélange Acacia mangium,

Gmelina arborea et Albizzia falcata et fruitiers divers avec dix espèces (type Ras 3.4), à Trimulia, Kalimantan-ouest en Indonésie, 2005.

Photo E. Penot.

\section{Conclusion}

La diversification de la production permise par ces pratiques agroforestières favorise une plus grande sécurité des revenus, une certaine minimisation des risques, ainsi que de meilleures valorisations et productivités des terres et de la main-d'œuvre.

Ces pratiques combinant des espèces pérennes avec l'hévéa peuvent permettre une amélioration considérable de la productivité du travail et l'obtention d'un système de culture compétitif si les espèces, les dispositifs et les densités de plantation sont soigneusement sélectionnés. Les systèmes simples sont adaptés localement à une combinaison de deux plantes à écologie similaire permettant une diversification sur le même espace. Les systèmes complexes résultent souvent d'une stratégie différente où la repousse forestière permet des externalités positives sur la biodiversité et la diminution des ressources en capital et en travail pour la mise en place, par rapport aux monocultures (lutte contre les adventices).

Mais ces pratiques, même si elles existent localement, sont en fait insuffisamment définies et caractérisées. Si les jungle rubber d'Indonésie sont assez bien documentés, ceux d'autres pays tels le Nigeria, couvrant pourtant plus de 100000 ha, ou la Malaisie (Sarawak) ne le sont pas. II existe également peu de recherches (effectuées ou réellement recensées ou disponibles) dans ce domaine en particulier, si elles sont comparées aux travaux liés à la monoculture (il existe en revanche beaucoup de rapports et de littérature grise). Cela peut s'expliquer par le fait que le monde de l'hévéaculture, et en particulier celui des grandes plantations jusqu'à la fin des années 1990, est un mode relativement conservateur où persistent des phénomènes d'inertie sur le plan technique, avec le modèle de la monoculture stricte et une plante de couverture en interligne. Même si certaines d'entre elles ont testé plusieurs possibilités (bois d'hévéa en intercalaire chez London Sumatra en Indonésie ou Michelin avec les fruitiers au Brésil), la plupart n'ont pas été retenues car les modes de production des grandes plantations ne sont pas compatibles ou rentables vis-à-vis des nécessités de production fruitière ou de bois d'œuvre (se pose le problème de calage des cycles, parmi d'autres). En revanche, les mêmes associations sont nettement plus intéressantes pour les petits producteurs compte tenu de la satisfaction d'un certain nombre de besoins grâce aux agroforêts, où l'autoconsommation aboutit à des économies relativement importantes (bois, fruits, vannerie, etc.).

La durabilité écologique et économique, la minimisation du risque, l'optimisation des facteurs de production (foncier, capital et surtout travail), l'intégration possible de cultures sur le long terme à un coût marginal (le bois) et la diversification des revenus sont des facteurs extrêmement positifs pour l'avenir de l'hévéaculture agroforestière, non seulement dans les régions traditionnelles de production mais également dans les zones nouvelles. L'expérimentation locale en milieu paysan en partenariat, l'accès aux marchés (fruits et bois) et une législation favorable au droit de propriété des arbres sont des préalables à tout développement régional important. Enfin, la prise en compte des externalités positives sur la biodiversité végétale, la fertilité des sols, la lutte anti-érosive et la valeur « puits de carbone » représentent des enjeux importants pour le futur de ces systèmes. L'hévéa est, en effet, la seule plante cultivée inscrite dans le Mdp (mécanisme de développement propre, issu du protocole de Kyoto) et donc éligible au même titre que les forêts pour sa valeur « carbone ».

Les espèces, à ce jour, les plus prometteuses pour l'utilisation en association avec l'hévéa sont indiquées ci-après. 


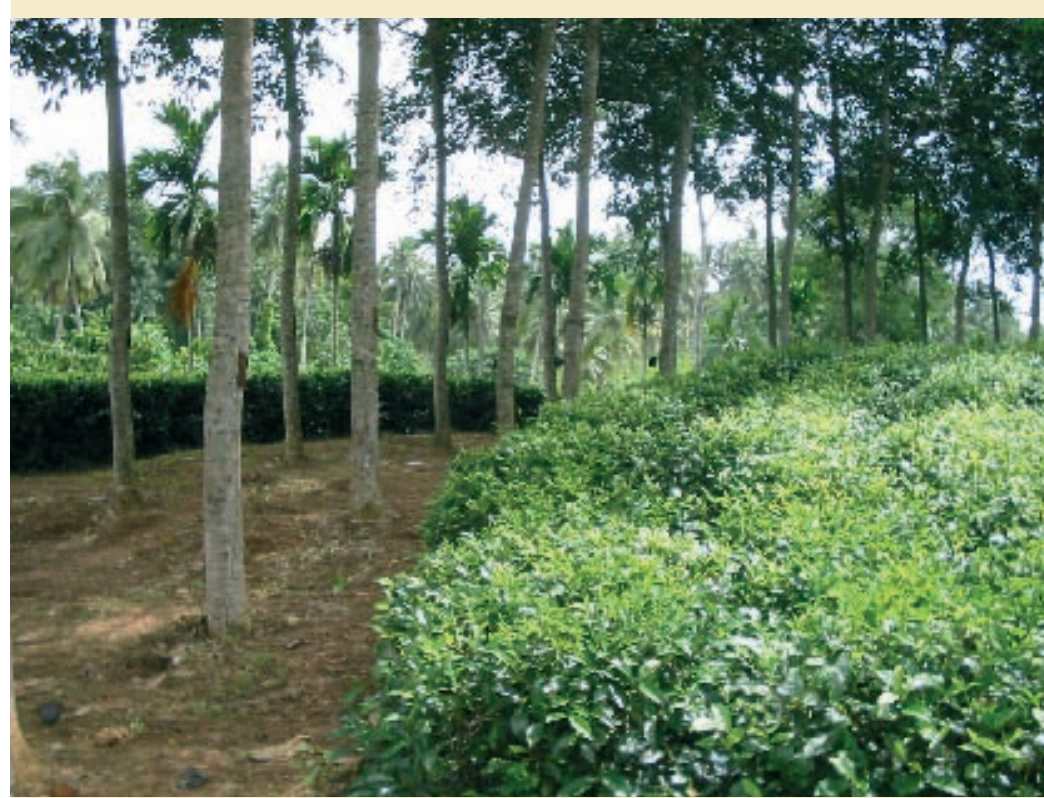

Photo 17.

Thé en intercalaire d'hévéa avec double interligne de $12 \mathrm{~m}$, plantation industrielle au Sri Lanka, 2005.

Photo E. Penot.

- Les arbres fruitiers avec un marché et des débouchés importants dans tous les pays asiatiques et la plupart de ceux d'Amérique latine (Colombie, Brésil, Guatemala...), où se développe le marché des fruits ou d'associés. La principale contrainte à la valorisation réside dans l'accès global au marché, national ou international, et dans les infrastructures d'acheminement de produits hautement périssables. Les marchés nationaux sont importants pour le duku, le jengkol et le petai, notamment en Indonésie. En Colombie, la diversité des fruits locaux est porteuse de combinaisons avec l'hévéa extrêmement intéressantes. Certains fruitiers produisent en période immature (ananas, banane, palmito) et d'autres produisent en même temps que l'hévéa (durian, rambutan, duku).

- Divers arbres à usages multiples et tolérants pour l'ombre, en vue de la production de bois d'œuvre ou d'autres produits non ligneux. À titre d'exemple : le thang, Litsea grandis, le khayom, Shorea roxburghii, le thamsao, Fagraea fragans, et le neem, Azadirachta indica.
- Les arbres à croissance rapide, soit pour le bois de feu ou la pâte à papier, soit pour des raisons écologiques (lutte contre l'imperata par ombrage). Gmelina arborea et Acacia mangium présentent un haut potentiel pour l'agroforesterie (pour le bois énergie en zone intensément déboisée). Toutefois, leur croissance très rapide peut être préjudiciable à celle de l'hévéa en période immature et c'est ainsi que Acacia mangium est nécessairement coupé dès la quatrième année dans les essais Ras 3 en Indonésie ; car, faute de contrôle, cette essence forestière peut entraîner une baisse significative de la croissance, puis de la production des hévéas.

- Les arbres de bois d'œuvre. Face à la déforestation croissante des zones de forêt en Amazonie et en Asie du SudEst, la demande de bois de qualité (teck et diptérocarpacées) est de plus en plus forte. Seuls les systèmes de culture agroforestiers ayant des cycles longs (d'au moins trente années) et un revenu assuré par une plante pérenne tel l'hévéa seront à même de pouvoir répondre efficacement à cette demande pour un coût très marginal pour le petit planteur. Les contraintes de valorisation du bois issu des agroforêts sont souvent de type institutionnel, où l'État s'arroge le droit de coupe et de commercialisation des grumes par le biais de concessions accordées à des groupes privés. Ces contraintes sont un peu partout en cours de disparition et les exemples rencontrés dès 2005-2007 tant en Indonésie qu'au Ghana montrent que le prochain producteur forestier dans ces deux pays risque bien d'être le planteur d'hévéa ou de cacao.

- Les espèces pérennes intercalaires en large interligne telles que le café, le cacao ou le thé. Quant au rotin, il est à mettre en place en fin de cycle, autrement des espèces de rotin risquent de disparaître de leur environnement naturel qu'est la forêt. De telles plantations peuvent être économiquement valables en Malaisie où le potentiel existe pour la participation des paysans aux transformations secondaires et tertiaires du produit.

Les possibilités d'agroforesterie sont multiples et importantes, et dépendent des législations locales sur le mode de tenure des arbres (pour les arbres à bois de valeur) et les marchés. Les cultures annuelles intercalaires, plus ou moins intensives, permettent de valoriser l'espace et de générer un revenu en période immature qui est la plus critique pour le producteur et d'augmenter la productivité globale du travail des systèmes puisque les arbres profitent de l'entretien des cultures. Malgré l'éloignement, si les fruitiers sont intéressants à proximité des villes ou le long des grands axes routiers, les arbres de bois d'œuvre sont promis à un grand avenir, du fait du déboisement intensif dans de nombreux pays tropicaux. 
BURANATHAM W., CHUGAMNERD S., KONGSRIPUN S., 1997. Agroforestry under rubber plantation in Thaïland. Thaïland/Malaysia Technical Seminar on Rubber, Phuket, Thaïlande, 1997, 11 p.

CHAMBON B., 2001. De l'innovation technique dans les sociétés paysannes: la diffusion de la monoculture clonale d’hévéa à Kalimantan Ouest (Indonésie). Montpellier, France, Cirad, 305 p.

COURBET P., 1996. La place de l'hévéa dans la transformation d'un système agraire de deux groupes ethniques du Xishuangbanna (Chine du Sud), les Hani et les Dai. Étude de deux villages en Chine du Sud. Mémoire de fin d'année, Cnearc/Esat, Montpellier, France, 90 p.

GOUYON A., 1995. Paysannerie et hévéaculture : dans les plaines orientales de Sumatra, quel avenir pour les systèmes agroforestiers ? Thèse de doctorat, Ina-Pg, Paris, France, 433 p.

GRIST P., MENZ K. M., THOMAS, 1995. A modified version of the BEAM agroforestry rubber model : smallholders in Indonesia. Canberra, Australie, Australian National University, Centre for Resource and Environmental Studies, Working papers, $30 \mathrm{p}$.

IMBACH C., 1995. Caractérisation de la diversité des systèmes de culture associant hévéas, cultures annuelles et cultures pérennes dans le bassin de Cotabato a Mindanao (Philippines). Mémoire Cnearc/Esat 1, Montpellier, France, $81 \mathrm{p}$.

LECOMTE J., 2001. Modélisation des exploitations hévéicoles : districts de Sanggau et Sintang, province de West Kalimantan. Mémoire de fin d'études, Enitac, Clermont-Ferrand, France, 50 p.

MARTIN L. 2005. Caractérisation des systèmes de production à base d'hévéa dans six villages du district de Sanggau, Kalimantan Ouest, Bornéo, Indonésie. Montpellier, Ina-Pg/Icraf/ Cirad, $147 \mathrm{p}$.

MICHON G., DE FORESTA H., 1991. Agroforesteries indonésiennes : systèmes et approches. Paris, France, Orstom, $12 \mathrm{p}$.

NIAZ A. K., SUDIBYA K. K., 2000. Sustainable land management with rubberbased agroforestry : a Bangladeshi example of uplands community development. Sustainable Development, 8 (1) : 1-10.

PENOT E., 1997. Associated trees with rubber in Rubber Agroforestry Systems (RAS). In : Icraf workshop on « Domestication of agroforestry trees ", Gadjah Mada University, Jogyakarta, novembre 1997, Bogor, Indonésie, 11 p.
PENOT E., 1997. From shifting agriculture to sustainable rubber complex agroforestry systems (jungle rubber) in the peneplains of Sumatra and Kalimantan in Indonesia : innovations in local rubber based cropping systems. In : Ruf F., Lançon F. (éd.). Indonesia : upland agricultural technology study. Montpellier, France, Cirad.

PENOT E., 1999. Techniques agroforestières en hévéaculture, expérimentation en milieu paysan et analyse systémique des systèmes de production. Rapport de mission de formation en Colombie pour le programme Plante. Montpellier, France, Cirad-Tera, 29 p.

PENOT E., 2001. Stratégies paysannes et évolution des savoirs : l'hévéaculture agroforestière indonésienne. Thèse de doctorat, Faculté des sciences économiques, Université Montpellier I, France, 360 p.

PENOT E., 2005 a. Intérêt et potentiel de la modélisation des exploitations agricoles avec le logiciel Olympe pour une prise en compte de l'agroforesterie dans les stratégies paysannes dans un contexte de diversification des cultures pérennes. Rapport de mission. Montpellier, France, Cirad, 45 p.

PENOT E., 2005 b. The rubber production sector review in Sri Lanka. Rapport Fao/Banque mondiale, $80 \mathrm{p}$.

PENOT E., 2006. Processus d'innovation et crises multiples : les hévéaculteurs indonésiens dans la tourmente. In : Caneill J. (éd.). Agronomes et innovations : $3^{\mathrm{e}}$ édition des entretiens du Pradel. Actes du colloque des 8-10 septembre 2004. Paris, France, L'Harmattan.

PENOT E., RUF F., 2001. Rubber cushions the smallholder : no windfall, no crisis. In : Gérard F., Ruf F. (éd.). Agriculture in crisis : people, commodities and natural ressources in Indonesia, 1996-2000. Montpellier, France, Cirad, Londres, Royaume-Uni, Curzon Press. En version française : Agriculture en crise : populations, matières premières et ressources naturelles en Indonésie, 1996-2000. Cirad/Karthala, 422 p.

PENOT E., ESCHBACH J.-M., 2005. Farmers'strategies and improved rubber agroforestry systems in Indonesia in 2005. Rapport de mission d'appui au Srap/Icraf. Montpellier, France, Cirad, 80 p.
RUF F., DEHEUVELS O., AKE ASSI L., SARPONG D., 2006. Intensification in cocoa cropping systems : is agroforestry a solution for sustainability? The Case of Manso Amenfi, Western region, Ghana. In : Quinzième Conférence internationale sur la recherche cacaoyère, San José, Costa Rica, 9-14 octobre 2006, vol. I, p. 355-364.

SAINT PIERRE C., 1989. Agroforestry in tropical China : traditional systems and current evolution. Thèse de $3^{e}$ cycle, Université des sciences et techniques du Languedoc, Montpellier, France, $89 \mathrm{p}$.

SIMIEN A., 2005. Caractérisation socio-économique et modélisation des exploitations hévéicoles du sud de la Thaïlande. Stage thématique et méthodologique de $2^{\mathrm{e}}$ année. Montpellier, Ensam/Istom, Inh, Psu/Hat Yai, Thaïlande, $45 \mathrm{p}$.

TAHUNAN L., 1996. Economic evaluation of agroforestry : planting of rubber with Sentang and rubber with Jati. In : Annual report of the Rubber Reseach Institute of Malaysia. Kuala Lumpur, Malaisie, Rrim.

WIBAWA G., 2000. Rubber based Agroforestry research in Indonesia. In : Irrdb Proceedings, 12-14 septembre 2000, Bogor, Indonésie, 31 p.

WIBAWA G., PENOT E., AKIEFNAWATI R., WILLIAMS S., 1997. Main agronomic results of RAS on-farm experimentation network in Jambi. In : Icraf/Srap Workshop on Rubber Agroforestry Systems in Indonesia, Bogor, Indonésie, 29-30 septembre 1997, 20 p.

WULAN Y. C., BUDIDARSONO S., JOSHI L., 2006. Economic analysis of improved smallholder rubber agroforestry systems in West-Kalimantan, Indonesia. Implications for rubber development. Bogor, Indonésie, World Agroforestry Centre (Icraf), Working document.

ZHENG HAISHUI, HE KEJUN, 1997. Intercropping in rubber plantation and its economic benefit. Research Institute of Tropical Forestry, Caf (Chine), Crdi (Canada). 